\title{
Lezama Lima y la poesía subjetiva del creador
}

\section{Lezama Lima and the subjective poetry of the creator}

\author{
Francisco Javier Hernández Quezada \\ Universidad Autónoma de Baja California, México
}

Resumen: En este trabajo reflexiono en torno a la propuesta poética del escritor cubano José Lezama Lima (1910-1976), y subrayo sus precisiones literarias al enfatizar la labor perceptiva del sujeto frente a los fenómenos del mundo; sobre todo, de esta suerte, el papel de la mirada como instancia central del proceso creativo en el escenario -siempre cambiante- de la realidad.

Palabras clave: poesía, subjetividad, imagen, mundo, realidad.

Abstract: In this essay I reflect on the poetic proposal of the Cuban writer José Lezama Lima, and underline the literary details that express when he prioritizes the perceptive work in front of the world; above all, in this way, to the paper that the gaze as central instance of the creative process in the -always changingscenario of reality.

Keywords: Poetry, Subjectivity, Image, World, Reality.

Recibido: 12 de noviembre 2016 Aceptado: 03 de abril de 2017 
R esulta indudable que, desde la perspectiva de José Lezama RLima, el ejercicio poético se convierte en punto de partida para la captación integral de la realidad. Apoyado en el principio rector de que el lenguaje aprehende las sustancias últimas de las cosas, el poeta cubano entiende que semejante labor favorece la manifestación de una expresividad totalizadora, la misma que atrapa el dinamismo del exterior al tiempo que aquél que se despliega, con destreza, en el universo de lo inmaterial. Concretamente hablo de ese ejercicio profundo que permite conocer la lógica del entorno, de sus manifestaciones (de sus ipotencialidades!). Pero también del rol que el sujeto creativo interpreta después de mirarse de otra manera y comprender que su labor ha de ser la de promover la alteridad de aquellos fenómenos que resultan sugestivos si se observan a través del tamiz fecundante del arte y la invención.

En especial, el interés de Lezama Lima por definir el sentido de la escritura poética se detecta desde su época de juventud (década de los treinta del siglo pasado), ${ }^{1}$ momento en el que concibe la necesidad de apuntalar un modelo literario que conjugue los rasgos de lo evidente y trascendental, y además transporte a "una región donde la sobreabundancia [anule] el determinismo empírico y el contrasentido lógico" (Yurkievich, 1997: 487). Poesía, por ende,

${ }^{1}$ En términos generales, esta reflexión juvenil se plasma en el texto "El coloquio con Juan Ramón Jiménez": diálogo de juventud en donde, como he apuntado en otro lugar, Lezama Lima realiza un "análisis del ejercicio poético: un examen que, cierto, aduce esa serie de pensamientos antropológicos, cercanos al estudio de la identidad, pero que están al servicio de la labor artística. Consecuentemente, para sustentar este diálogo, son repetidas las veces en que Lezama Lima y Juan Ramón traen a colación los nombres de varios autores que, con sus propuestas, explicitan lo que debe y no debe ser la escritura poética. Por sus implicaciones, el más comentado de todo ellos es Paul Valery: escritor que [...] contraviene el sentido de la poesía, precisamente al apostar por un intelectualismo creativo que recusa las percepciones íntimas y espontáneas" (Hernández Quezada, 2011:23). 
expansiva, que celebra las manifestaciones de la totalidad: considérese, en fin, que su "videncia" (Oviedo, 2002: 152), desde el principio (y desde siempre), produce un significado distinto, disímil, gracias al cual el interlocutor lezamiano descubre múltiples cosas, entre ellas las facetas diversas del contexto en el que se desenvuelve y asume una posición; en el que se relaciona, asimismo, con los demás y configura una visión compleja del exterior.

Por esta razón, la idea central de Lezama Lima es la de transformar la mentalidad atávica de sus congéneres (los cubanos) en pos de contravenir las situaciones que los condicionan y que, en el contexto caribeño, ha supuesto la reválida de la normatividad, del apego a los esquemas trucados que violentan un significado: el de la tradición (Rojas, 2006: 58).

Consecuentemente, el artefacto poético es el medio ideal para que la subjetividad se manifieste y abrevie la efusión dialógica de una mentalidad que, a fuerza de contravenir las verdades, traduzca los secretos del mundo y demuestre algo en particular: que "las infinitas posibilidades del suceder” (González Cruz, 2000: 435) se relacionan también con prácticas de vida, con experiencias del sujeto, las cuales lo trasladan a otra dimensión. Tan es así que Lezama Lima afirma que gracias a los poderes heterodoxos del código poético es fácil demostrar que el universo material se transforma con frecuencia, manifestando eso que Carmen Ruiz Barrionuevo denomina el "mundo de lo incondicionado": un "mundo" donde

reside la poesía, [...] el mundo superior perdido por el hombre que se encuentra sumido en un mundo causal, plural, temporal y espacial pero que aspira a ese otro mundo de la unidad y de cuya comunicación surge la poesía, porque a la poesía se llega por iluminación y responde a un desafío del ser; nace de la palabra -por la palabra participamos en el verbo universal-, pero no de la palabra cotidiana, sino de la palabra primigenia, tal y como surge de la 
imaginación primitiva, que no nos remite a los objetos, sino que los crea, los reproduce y conforma (Ruiz Barrionuevo, 1980: 40).

Como Ruiz Barrionuevo indica, el "mundo de lo incondicionado" es el mundo de lo interior, garante de la irrupción poética y de ese lenguaje singular, autónomo, que cuestiona los esquemas notorios del lugar común; es un "mundo" secreto, invisible e interior, que remite a la idea de la "unidad" y favorece el surgimiento de la percepción total (esto es: de la percepción reveladora). Gracias a ello, Lezama Lima entiende que la poesía es la experiencia a solventar, máxime si pensamos en los esquemas conceptuales de la actualidad, vinculados con un tipo de saber que, como menciona Edgar Morin, opera

mediante la selección de datos significativos y de rechazo de datos no significativos: separa (distingue o desarticula) y une (asocia, identifica); jerarquiza (lo principal, lo secundario) y centraliza (en función de un núcleo de nociones maestras) [, en términos de que tales] operaciones, que utilizan la lógica, son de hecho comandadas por principios «supralógicos» de organización del pensamiento o paradigmas, principios ocultos que gobiernan nuestra visión de las cosas y del mundo sin que tengamos conciencia de ello (Morin, 1997: 28).

Poeta que busca la trascendencia: Lezama Lima sabe muy bien que la subjetividad descansa en el ojo del observador, aspecto que le permite detectar las partes del conjunto y otorgarles sentidos flexibles que intensifican los efectos de la percepción. "Pues, de acuerdo con Lezama Lima, la subjetividad del creador debe fundamentar los principios poéticos de ese lenguaje indeterminado, profuso, en ocasiones críptico, cuyo objetivo principal es desmantelar la idea de que las convenciones son puertas de ingreso al espacio del cambio y la transformación, y salidas legítimas para 
aquellos que respetan el sentido coercitivo de la ley. De ahí que, contrariamente, las visiones subjetivas del yo traduzcan variables problemáticas de la realidad, captando los dejos de una expresión inestable, imprevisible y dialógica que para nada se relaciona con los del sistema de producción; una realidad significativa, dinámica y rizomática, sustentada en la multidimensionalidad de los fenómenos, concebidos -y vistos- como sucesos relevantes del yo.

De esta suerte, insiste Lezama Lima, la apuesta por rescatar el sentido de la $i m a g o^{2}$ garantiza que el lenguaje poético enfatice el papel constructor del sujeto y geste el "testimonio del no ser", ya que, profuso, da fe de lo intangible (de lo incorpóreo) como complemento de la realidad; incluso, de una realidad compleja que, observada desde la óptica artística, establece el "diseńo de su progresión" (Lezama Lima, 1977: 152-153). Desde tal criterio, sugiero, nada más ajeno a la especificidad cognitiva de la modernidad que esta manifestación subjetiva del creador: se entiende, ente rebelde que tras manifestarse mediante el código poético, violenta las acepciones selectivas del discurso racional, modificando sus

${ }^{2}$ De acuerdo con las ideas de Sergio Ugalde Quintana, siempre que nos topamos con dicha categoría, en el corpus lezamiano, estamos obligados a entender que, "en tanto representación mental de los fenómenos de la realidad, es un principio de conocimiento o de contacto con el mundo; de igual manera, [que] es uno de los elementos retóricos más comunes de la poesía. Sin embargo, [tales] facetas no fueron las únicas dimensiones que el poeta destacó. Al adentrarnos en sus ensayos, otros ámbitos empiezan a aparecer: la imagen al ponerse en relación con la historia se acerca a la idea del mito" (Ugalde Quintana, 2011: 60) y a la del arquetipo. En todo caso, hablar del nexo que Lezama Lima establece entre la imagen y la poesía colige la cuestión de que estamos ante un hecho de carácter sagrado, tal como lo expresa en su ensayo "Sobre Paul Valéry" (1945), en el que vincula "esa idea con el término de transubstanciación en Santo Tomás": "Dios, asegura el padre de la Iglesia, es la figuración; el Hijo, por su parte, es la imagen de él. [...] La percepción visual, entrega, en primera instancia, una representación en la conciencia. El ser de los objetos, al percibirlos, no puede ser sino su representación o su imagen" (Ugalde Quintana, 2011: 58). 
esquemas y cuestionando las valoraciones sistémicas de la lógica, como explica Morin. Nada, en consecuencia (insisto), más contraproducente que tal evidencia del interior, si se entiende que la imagen poética es la resultante de una captación sagrada, alejada de la superficialidad de la mirada pragmática que, sabemos, se vuelca en las formas del exterior y no en los valores que afloran en su contraparte: la subjetividad.

Por lo demás, la discusión que Lezama Lima plasma en su importante ensayo "Coloquio con Juan Ramón Jiménez" evidencia el temprano interés del escritor por reflexionar acerca del ejercicio literario a partir de las exigencias del "paisaje" local y de los sentidos populares concebidos para expresar un deber ser (CruzMalavé, 1994: 31). En sí, la discusión supone comprender que si bien existen una serie de condiciones externas que motivan la práctica literaria (las injusticias, las cuestiones raciales, los colores de la estampa local), éstas deben evaluarse con detenimiento y rigor, tomando en cuenta las necesidades creativas del sujeto, antes que las demandas colectivas que existen y reclaman un compromiso puntal. Se indica, así, que el poeta debe ser fiel a la tradición para encontrar las claves de lo trascendental, de lo duradero; pero, a la par, que debe correr riesgos, apostando por lo indeterminado y dejándose llevar por el impulso de sus demonios, resultado del existir.

El poeta, luego, ha de escuchar su voz, lo que le permitirá observarse en cuanto tal, es decir, en cuanto ente activo que participa en el espacio social y postula un modelo creativo de inspiración personal, cuyo desarrollo dependerá de los riesgos que asuma y le garanticen la concreción de ese "sistema poético del mundo, y aun de la historia", apto para subvertir los esquemas formales del "realismo anacrónico" (Sucre, 1990: 157). Lo cierto es que se exige el compromiso (Lezama Lima dixit), hecho que delimita un campo de acción: el de la subjetividad; un campo condicionado, en el 
que la individualidad no existe o está supeditada a las necesidades afectivas de la participación (Hernández Quezada, 2011: 71-81).

Frente a esto, la sugerencia del poeta conlleva un procedimiento a través del cual el yo 1) atiende el "impulso" de la "imagen" (Cruz-Malavé, 1994: 6) y 2) pondera la certeza de que "la riqueza infantil de la creación” (Lezama Lima, 1977: 45) es la fuerza que transforma el exterior: la energía que modifica el paisaje, toda vez que influye en la persona y prescribe su movilidad. De esa manera, la poesía ha de convertirse en el punto de partida de un reconocimiento interior que, a la vez que expresa los códigos alternos del conocimiento personal, evidencia el azar de los conjuntos, de las atracciones, según la propuesta poética que se detecta desde su primera libro publicado: Muerte de Narciso (1937): libro en el que se exhibe esa "imagen [dinámica,] que se mueve en el espacio de una escritura para exhibir sin pudores su potencia metamórfica" y además en la que se revela esa "dimensión que no existe para la escritura: la superposición de los objetos en una vertical que anhela lo profundo" (Coronado, 2015: 119).

Por supuesto, tal vocación de ruptura y aspiración a conquistar la dinámica subterránea del lenguaje habilita a Lezama Lima a indagar en aquello que es complejo y oscuro, debido a que, como afirma en su famoso ensayo La expresión americana (1957), sólo "lo difícil es estimulante; sólo la resistencia que nos reta es capaz de enarcar, suscitar y mantener nuestra potencia de conocimiento" (Lezama Lima, 1993: 49). En ese tenor, entiendo, es que la búsqueda de lo trascendental moldea sus indagaciones, hasta el punto de que los hallazgos poéticos que realiza siempre dependen de la representación de aquellas situaciones que, sugestivas, suscitan una fuerza.

Pertinaz en este punto, Lezama Lima sugiere que las limitativas de la "sensibilidad insular" (propias de un sujeto menor) son el resultado de los apegos del perceptor, principalmente al dejarse llevar 
por la inmediatez de la realidad y las distorsiones que semejante contacto genera. La idea, por ende, que busca difundir, refiere la urgencia de transformar la "sensibilidad" individual como acción necesaria para difuminar las fronteras insulares y proyectar el sentido original de la creación.

¿Qué supone entonces, para él, el ejercicio estético? Sin duda, la urgencia de establecer una teleología individual que modifique el devenir de la expresión; que transforme la política del(os) afecto(s), con la certeza de que los cambios generados influyan en el devenir social de los sujetos y su personalidad. En esa línea, Lezama Lima se muestra reacio al ejercicio técnico del poema; es decir, al ejercicio preconcebido y sustentado en el método de la razón, ya que comprende que entender de tal manera el trabajo creativo es cosificar el significado de lo inmaterial y, peor todavía, basarse en categorías reconocibles que unifican lo que, por diversos medios, reclama espontaneidad, frescura y distinción. Igualmente, el autor de Paradiso (1966) asume que validar el poema en dichos términos colige la frustración de la universalidad, puesto que cada vez que su performance se condiciona, según los deseos nativos de la "sensibilidad", se logra la infatuación "insular": verdadero dolor de cabeza para quienes consideran que el arte trascendental en poco o en nada se relaciona con los influjos pintorescos del color local y sus medios de difusión.

En virtud de lo mismo, Lezama Lima entiende que es difícil aprehender con una "técnica coherente" los "elementos inefables" (Lezama Lima, 1977: 54) de la experiencia individual. Dispersos e indescifrables (considera), tales "elementos" reclaman una modalidad sugerente, cuya libertad estética fortalece la complejidad de la imagen a rescatar, al tiempo que el desalojo de esa "tensión que provoca la aparición [rígida] del sentido", logrando que sus "leyes de gobierno sintáctico" (Lezama Lima, 1977: 55) entren en crisis y capten los aspectos más banales de la realidad. Bajo tal criterio, 
se entiende el porqué "la lógica maravillosa de las palabras" manifiesta tanto la ley de los cuerpos (y de "las almas disímiles") como "la vida íntima de los elementos" (Lezama Lima, 1977: 55); huelga decir: esa "vida íntima" que refleja un dinamismo impar, un dinamismo único, el mismo que hace las veces de alternativa simbólica del exterior.

Para Lezama Lima, la necesidad de proponer otro modelo poético -fincado en las parcelas de la subjetividad- descansa en la importancia de modificar el rumbo cubano, dado que, consciente de los males simbólicos, prioriza alternativas viables que favorecen el devenir de la expresión; que también permiten el bosquejo de un modelo teleológico, apto para modificar los hábitos de quienes se dedican al arte y a la cultura, y de quienes disfrutan de este trabajo y exigen una tarea creativa de mayor tenacidad.

Es importante, en tal circunstancia, la implantación de una directriz que libere los influjos de la "sensibilidad". Y lo es, porque, desde la perspectiva lezamiana, la poesía ha de expresar la apertura epistémica de una percepción que no se queda, en exclusiva, con los datos del exterior sino que, más bien, da un paso más allá y capta el flujo continuo de la otra realidad. ${ }^{3}$

Sobre este punto, recordemos los argumentos de Cruz-Malavé, para quien el "sistema poético del mundo" lezamiano se constituye en un sistema de integración-transformación colectiva, mediante

3 "Es esta una poesía empedernidamente hedónica. De inmediato se propone como objeto estético, halagador, sensual, suntuario. Deleite ocioso, desinteresado gozo, arrobo beatífico, saca a quien se entrega al 'mentidor robador' por completo de todo menester, de toda vicisitud mundanal. Es juego que escinde el continuo de la normalidad convencional. Posibilita el contacto con otra realidad por desacato al orden del realismo utilitario. Implica interregno festivo, ajeno al dominio de la razón pragmática. Paréntesis tempoespacial, permite ingresar a una esfera autónoma. Estado de excepción donde la función lúdica comulga con la poética, tiende a ritualizarse: lo cultural se vuelve cultural" (Yurkievich, 1997: 485). 
el que se postula, individualmente, la mirada compleja del creador y su misión social, si es que se me permite llamarla así:

Contra el peso unívoco [...] de la historia que subordina, margina o limita las posibilidades de creación de lo moderno y de lo americano, Lezama propone este "mito del insularismo"; un sistema poético total cuyo objeto es convertir la marginación de lo contemporáneo y de lo americano, en centro trascendental, en origen de posibilidades infinitas. Centrar la isla de Cuba y centrar su devenir histórico desarraigado, como propone Vitier en Lo cubano; volver a la "imagen" paradisíaca de la isla, es esa la meta del "mito del insularismo” en el "Coloquio” (Cruz-Malavé, 1994: 34).

Como explican estas líneas, el planteamiento lezamiano respecto a la creación se resume en el intento de contravenir el mal histórico de la endogamia, y exigir cuotas creativas que eleven la percepción del lector, justamente al comunicarle el significado profundo de la imagen y darle a entender que el cambio radical de la subjetividad se encuentra en la consecución de los objetivos trazados.

Con tal criterio, Lezama Lima comprende que la reincidencia del modelo implica subrayar las posibilidades del poeta, y del lector, debido a que el mensaje transmitido configura la mirada personal de las cosas, según se expresa en su obra cumbre, Paradiso, justo en el momento en que reitera los poderes transformativos de la imago y acentúa el detalle de que la separación de los elementos perceptuales es una consecuencia del "sofoco"; es decir, de esa imposición inmediata y no trascedente del exterior, que pronto desaparece al aflorar el rico mundo de la subjetividad, y trastrocar el devenir de las formas humanas e inhumanas con las que se establece relación; a este respecto, el poeta apunta, en un diálogo esclarecedor: 
El separatismo surge de ese sofoco. Pero sólo nos separamos, en una dimensión de superficie, de aquello que sabemos que es una fuerza demasiado oscura, indomeñable para nuestra progresión. Pero el animal fuerte, toro del demonio, un tanto cegato, apenas precisa que alguien se le quiera separar, lo mima, se encariña con él, de noche revisa las piezas para comprobar el pequeño adormecido. Existe el Eros de lo que se nos quiere escapar, tan fuerte como el conocimiento sexual de la ausencia. En el animal poderoso, la conciencia de lo que se le quiere separar es el nacimiento de un ojo. Entonces siente al lograrse la separación, la pérdida de un tentáculo de visibilidad. Y brama rizando el cielo. Es una hermosa pelea. El espíritu de la separación es instantáneo y por eso llora. $\mathrm{Al}$ realizarse tiene que estar ya en otro banco de arena (Lezama Lima, 1988: 118).

El "nacimiento" del "ojo", el avance del "ojo", la voluntad del "ojo"; Lezama Lima parte hacia la búsqueda trascendental con los recursos poéticos de la sintaxis y su engendro barroco-suprarreal de toros endemoniados que trastocan la percepción. Y no sólo eso, con dichos recursos deja de lado lo más dañino, en relación con la mirada: la "dimensión de superficie"; esa "dimensión" que debe considerarse como complemento de la totalidad: como elemento visual-superficial, puesto que de no concebirse en tales términos se corre el riesgo de que el "sofoco" se transforme en una "fuerza demasiado oscura" que imposibilite "la progresión" de la subjetividad y del conocimiento productivo: esto es, del conocimiento integrador que revela los cauces internos del mundo material. De tal suerte, Roberto Friol tiene sobrada razón cuando enfatiza la sugestión de la imago en este fragmento, y precisa que son los "ojos" del observador y "su quehacer" analítico los que manifiestan un "frenesí de ver, de mirar, de observar, de contemplar, de vislumbrar", revelando un "inventario del poder de los ojos" que permiten, por ejemplo, que los "sueños" también sean "vistos" (Friol, 1988: 658). 
Pero, volviendo al principio, es de valorarse el planteamiento de Lezama Lima sobre el papel de la poesía como instancia rectora de la mentalidad, y del cambio individual que, entre otras cuestiones, suscita el surgimiento de un sinfín de visiones. Y más, todavía, si se atiende a que el ejercicio poético transforma la realidad observada y permite que el perceptor realice valoraciones efectivas que lo trasladan al territorio del mito y de la religión. Por eso, semejante ejercicio activa el proceso totalizador del conocimiento individual, bajo el criterio de reprimir el "sofoco" y desplegar los vínculos que el "ojo" subjetivo establece cada vez que se vuelca en la revisión de las partes, dejando de lado las precisiones del conocimiento unidimensional y fortaleciendo las que se vinculan con la apertura, con la asimilación. Esto, ulteriormente, permite que el sujeto perceptor (el sujeto poético) conozca las cosas de otra manera y participe de una experiencia espiritual que conecta al yo con lo trascendental-paradisiaco; con ese reino de la imago donde nada es lo que parece y la normatividad sistémica está fuera de sitio, particularmente si se insiste en la limitación y el apego a la perspectiva unidimensional.

Vivencia exhaustiva e integradora: para Lezama Lima la relación poesía-subjetividad resulta fundamental, en tanto el autor cubano advierte que esta última es la base para que la expresión se proyecte hacia otra dimensión y ventile los devaneos de un eros que conoce y recupera las variables secretas de la realidad "hasta formular [...] una teoría de la generación que aspira a interrumpir la causalidad natural [y a] fundar un reino donde las leyes de la creación se ejercerían no tanto contra-natura como sobre-natura” (de Armas, 2000: 22).

En conclusión: la propuesta de Lezama Lima estriba en la posibilidad de establecer, con todos sus recursos poéticos, el proyecto teleológico de la imagen; un proyecto que, amparado en las labores cognitivas de la subjetividad, encabeza la labor consciente e 
inconsciente de la indagación, de la penetración en el universo de la segunda naturaleza, donde los elementos se comunican intensamente, revelando su significado más profundo, y permitiendo que esta relación fructifique en un conocimiento más amplio de la realidad. O sea, un conocimiento diferente que, descubierto en sus diferentes proyectos, garantiza la legitimidad del caos o de eso que en su poema "Noche insular: jardines invisibles" define como el "rumor de pronto despertado" y que el poeta observa tanto en los rasgos del paisaje externo como en los del interno; apunta Lezama Lima en la primera estrofa:

Más que lebrel, ligero y dividido al esparcir su dulce acometida, los miembros suyos, anillos y fragmentos, ruedan, desobedientes son, al tiempo enemistado.

Su vago verde gira en la estación más breve del rocío que no revela al cuerpo su oscura caja de cristales. El mundo suave despereza su casta acometida, y los hombres contados y furiosos, como animales de unidad ruinosa, dulcemente peinados, sobre nubes (Lezama Lima, 2000: 118).

En "Noche insular: jardines invisibles", Lezama Lima refiere las imágenes del afuera urbano después de ser captadas por la conciencia poética, y de establecerse, aleatoriamente, los márgenes del universo personal. Por tanto, lo primero que se expresa es una focalización: la del "lebrel" (animal inerte que, una vez que ha sido visto, o fijado por la mirada) se transforma en algo más: en una especie de proliferación simbólica que, siguiendo los esclarecedores planteamientos de Irlemar Chiampi, suscita la multiplicación 
de la imagen y del significado; es decir, la "producción de signos, no entorno a una palabra, sino a un efecto de sentido o semema" capaz de producir "una cadena de signos que buscan tan sólo crear [los efectos de] una verosimilitud intratextual" (Chiampi, 2000: 188). Visto de ese modo, Lezama Lima capta el flujo torrencial de la imagen, revelando el desperezo del "mundo" y mostrando el surgimiento de una serie de figuras enlazadas entre sí que, por un lado y parafraseando el título del poema, muestran las características físicas de la noche habanera y, por otro, los espacios imperceptibles del universo interior. Las relaciones que el poeta establece, en consecuencia, son diversas, y se plasman en un discurso inconsciente pero revelador, que a la vez que esgrime los aspectos perceptibles del paisaje insular, admite el traslado y uso de los significados secretos, de los significados personales, que alimentan la pulsión de la verdadera creatividad (Hernández Quezada, 2011: 28).

En el presente texto, mi objetivo ha consistido en abordar los esquemas literarios de un escritor que, a lo largo de su obra, es fiel a la creencia de que la poesía es una cuestión trascendental, casi religiosa, que reclama esa apertura mental dispuesta a captar de otra manera el mundo de la realidad, o sea, dispuesta a 1) captar sus esencias para después 2) revelar un discurso preadánico, sin culpa alguna, que aliente la transformación perceptiva del yo y de los demás.

En efecto, creo que para agotar el tema se requeriría un trabajo más extenso, que diera fe de todos los procedimientos creativos de Lezama Lima, en sus variables poéticas, narrativas y ensayísticas. Pero, sin duda, hablar de este autor es hablar de un autor hiperbólico, que rebasa cualquier tentativa de simplificación, principalmente si partimos de la consideración de que su obra, llena de referencias y valoraciones crípticas, exige el desarrollo de una crítica valorativa, que indague, puntualmente, en la estructura profunda de las obras y revele "las constantes y regularidades que rigen la 
conformación del sistema; los nexos, los vínculos y relaciones que permiten la integración” (Carrió Mendía, 1988: 341).

Con lo anterior, Lezama Lima concibe un proyecto trascendental, en el que importa la mirada del sujeto, pero sobre todo, lo que trae consigo en sus adentros y lo diferencia de los demás; asimismo (agréguese), en el que importa la renuncia del esquema, de la perspectiva unívoca y simplificadora que convierte la existencia del sujeto en una vivencia pueril, desvinculada de las sugestiones y pulsiones secretas.

\section{Bibliografía}

Armas, Emilio de, 2000, "La poesía del Eros cognoscente", en José Lezama Lima, Poesía, Emilio de Armas (ed.), 2a edición, Madrid, Cátedra, pp. 11-72.

Carrió Mendía, Raquel, 1988, "La imagen histórica en Paradiso", en José Lezama Lima, Paradiso, Cintio Vitier (ed.), México, Colección Archivos, SEP, pp. 539-555.

Coronado, Juan, 2015, “Gongorismo de Lezama”, en Luzelena Gutiérrez de Velasco y Sergio Ugalde Quintana (eds.), Banquete de imágenes en el centenario de José Lezama Lima, México, Colmex, pp. 109-130.

Cruz-malavé, Arnoldo, 1994, El primitivo implorante. El "sistema poético del mundo", Amsterdam/Atlanta, Editions Rodopi B. V.

Chiampi, Irlemar, 2000, Barroco y modernidad, México, FCE.

Friol, Roberto, 1998, “Capítulo VI. Los ojos”, en José Lezama Lima, Paradiso, Cintio Vitier (editor), México, Colección Archivos, SEP, pp. 658-659.

González Cruz, Iván, 2000, Diccionario. Vida y obra de José Lezama Lima, Valencia, Generalitat Valenciana. 
Hernández Quezada, Javier, 2011, La imago mexicana en la obra de José Lezama Lima, México, Universidad Iberoamericana Puebla/Gobierno del Estado de Puebla.

Lezama Lima, José, 1977, Obras completas, t. II, Aguilar, México. , 1988, Paradiso, Cintio Vitier (ed.) México, Colección Archivos, SEP.

, 1993, La expresión americana, Irlemar Chiampi (ed.), México, FCE. 2000, Poesía, Emilio de Armas (ed.), 2a edición, Madrid, Cátedra.

Morin, Edgar, 1997, Introducción al pensamiento complejo, Marcelo Pakman (trad.) 3a reimpresión, Barcelona, Gedisa Editorial.

Oviedo, José Miguel, 2002, Historia de la literatura hispanoamericana. 4. De Borges al presente, $1^{\text {a }}$ reimpresión, Madrid, Alianza Editorial.

Rojas, Rafael, 2006, Tumbas sin sosiego. Revolución, disidencia y exilio del intelectual cubano, Barcelona, Anagrama.

Ruiz Barrionuevo, Carmen, 1980, El "Paradiso" de Lezama Lima (Elucidación crítica), Madrid, Ínsula.

Sucre, Guillermo, 1990, La máscara, la transparencia. Ensayos sobre poesía hispanoamericana, $1^{\text {a }}$ reimpresión, México, FCE.

Ugalde Quintana, Sergio, 2011, La biblioteca en la isla. Una lectura de La expresión americana, de José Lezama Lima, Madrid, Editorial Colibrí,

Yurkievich, Saúl, 1997, Suma crítica, México, FCE. 